Article

\title{
Thermodynamic Analysis of Pyrolusite for Dry Flue Gas Desulfurization
}

\author{
Wenhao Wang ${ }^{1, *}$, Fuzhong $\mathrm{Wu}^{2,3}$, Keke Wang ${ }^{2}$ and Huixin Jin ${ }^{2}$ \\ 1 School of Materials \& Metallurgy, Northeastern University, Shenyang 110189, China \\ 2 The Key Laboratory of Metallurgy and Energy Conservation of Guizhou, Guiyang 550025, China; \\ gutwfz@163.com (F.W.); kkwang19910122@163.com (K.W.); jinhuixin@sina.com (H.J.) \\ 3 State Key Laboratory of Complex Nonferrous Metal Resources Clean Utilization, Kunming 650093, China \\ * Correspondence: neu_whwang@sina.com; Tel.: +86-851-838-58242
}

Academic Editor: Yu-Pin Lin

Received: 2 December 2015; Accepted: 1 February 2016; Published: 25 February 2016

\begin{abstract}
Various approaches to flue gas desulfurization by low-grade manganese and high efficiency desulfurization in sintering enterprises were investigated, and the predominance areas of the $\mathrm{Mn} / \mathrm{Fe}-\mathrm{S}-\mathrm{O}$ system were constructed in this paper. Additionally, the areas in different temperatures were established based on the thermodynamic properties achieved from manuals. From the view of thermodynamics, manganese oxides were suitable and feasible for desulfurization at an appropriate temperature range from $393 \mathrm{~K}$ to $453 \mathrm{~K}\left(120^{\circ} \mathrm{C}\right.$ to $\left.180^{\circ} \mathrm{C}\right)$, which means that the $\mathrm{SO}_{2}$ of sintering flue gas could be removed directly without further cooling or heating. The analysis often showed that there was an overlap area of the Mn-S-O and Fe-S-O system, indicating that it would be a coexistence stability region of $\mathrm{MnSO}_{4}$ and $\mathrm{Fe}_{2} \mathrm{O}_{3}$, which provided a possibility of desulfurization by selective salvation without the sulfate and sulfide of iron forming. More importantly, the predominance areas of $\mathrm{Mn} / \mathrm{Fe}-\mathrm{S}-\mathrm{O}$ would offer an attractive way of determining optimum experimental conditions for dry desulfurization by low-grade manganese resources.
\end{abstract}

Keywords: low-grade manganese; desulfurization; thermodynamic analysis; predominance area

\section{Introduction}

$\mathrm{SO}_{2}$ was well-known as an undesirable contaminant being emitted into the atmosphere from the combustion of coal, the smelting of ores, and the production and consumption of petroleum and natural gas, increasing the damaging effects to the environment and public health. Although the $\mathrm{SO}_{2}$ concentration was very low, the total amount was huge [1]. Since 1970, flue gas desulfurization (FGD) has been attracting the attention of the world, with the dominant technology being the lime/limestone process due to its high efficiency and stability [2]. However, the present FGD technology has many disadvantages, such as high capital cost, large occupation of land area, large consumption of fresh water, and formation of secondary pollutants [3,4]; it is consequently not suitable for sintering flue gas. Many methodologies have been proposed to remedy such problems, such as dry FGD technologies, namely $\mathrm{SO}_{2}$-containing flue gases related with dry sorbets (lime or limestone), which were considered to be more suitable for flue gas desulfurization because of their low operating costs, high desulfurization efficiency without preheat before desulfurization, and lower water consumption [3,4].

Manganese oxides have received special emphasis as an absorbent for removing sulfur dioxide from flue gas. In early studies, investigators [5-9] indicated that pyrolusite slurry or manganese oxides could remove $\mathrm{SO}_{2}$ from flue gas with little negative impact on the environment. From a theoretical 
point of view, pyrolusite or manganese oxides have desirable properties: a high sulfur capacity, the ability to remove $\mathrm{SO}_{2}$ to a very low level, and the feasibility of formed manganese sulfate, which could soluble in the aqueous solution. From a technical point of view, the new technology paves the way to exploit and utilize low-grade manganese resources. However, during the process of absorption, the manganese dioxide in the pyrolusite was converted to dithionate [10], bringing pollution to the subsequent processing. The fuel gas of the sintering process discharge temperatures was about $120^{\circ} \mathrm{C}$ to $180^{\circ} \mathrm{C}[11,12]$. Therefore, the present work proposed a dry desulfurization technique employing low-grade manganese resources at a discharged temperature range from $393 \mathrm{~K}$ to $453 \mathrm{~K}$, where the flue gas from the sintering process could be desulfurized directly without further cooling or heating.

There were a number of studies that led to the consideration of manganese oxides or manganese-based sorbet for flue gas desulfurization. The earlier work, which was subsequently followed by kinetic studies, predicted manganese sulfate would not be thermodynamically feasible above approximately $1188 \mathrm{~K}[13,14]$. Kiang et al. [15] proposed a non-topochemical model at temperatures from $573 \mathrm{~K}$ to $723 \mathrm{~K}$ using manganese dioxide, assuming the reaction was irreversible and first-order with respect to $\mathrm{SO}_{2}$ concentration, and also proportional to the reacting surface area. Lacey et al. [16] reported a homogeneous model of the absorption of $\mathrm{SO}_{2}$ by $\gamma-\mathrm{Mn}_{2} \mathrm{O}_{3}$, and the data indicated that the absorption is controlled by both diffusion and chemical reaction. Ingraham et al. [17] measured the rate of absorption of $\mathrm{SO}_{2}$ by $\mathrm{MnO}_{2}, \mathrm{Mn}_{2} \mathrm{O}_{3}$ and $\mathrm{Mn}_{3} \mathrm{O}_{4}$ at temperatures between $573 \mathrm{~K}$ and $723 \mathrm{~K}$, finding the weight gain increased almost linearly with time. Li et al. [18] tested fixed bed absorption of $\mathrm{SO}_{2}$ by $\mathrm{MnO}_{2}$ and $\mathrm{Mn}_{2} \mathrm{O}_{3}$ and found the absorption capacity increased with the increasing surface area and decreasing specific gravity. Uno et al. [19] presented an empirical equation for the absorption of $\mathrm{SO}_{2}$ from flue gas with manganese oxide $\left(\mathrm{MnO}_{x} \cdot i \mathrm{H}_{2} \mathrm{O}: x=1.5-1.8, i=0.1-1.0\right)$, and found the reaction rate decreased with the increase in $\mathrm{MnSO}_{4}$ content in the absorbent and dropped sharply when the $\mathrm{MnSO}_{4}$ content reached about $30 \%-40 \%$.

The incentive of this present research was part of an ongoing project which aimed at developing a predominance area for dry desulfurization by low-grade manganese resources. According to the study, the predominance areas of $\mathrm{Mn} / \mathrm{Fe}-\mathrm{S}-\mathrm{O}$ would offer an attractive way of determining optimum experimental conditions for dry desulfurization.

\section{Theoretical Principles}

According to Kirchhoff, the Gibbs free energy was given by Equation (1):

$$
\Delta_{r} G_{T}^{\theta}=\Delta H_{298.15}^{\theta}-T \Delta S_{298.15}^{\theta}+\int_{298.15}^{T} \Delta c_{p} d T-T \int_{298.15}^{T} \frac{\Delta c_{p} d T}{T}
$$

In the $\mathrm{Mn} / \mathrm{Fe}-\mathrm{S}-\mathrm{O}$ system, the chemical reactions studied may be represented by the general stoichiometric equation:

$$
a A(s)+b B(g)=d D(s)+h H(g)
$$

When the reaction was at equilibrium, the Gibbs free energy could be expressed as:

$$
\Delta_{r} G_{T}=\Delta_{r} G_{T}^{\theta}+R T \times \ln k_{e p}=0
$$

With the equilibrium constant of this reaction (i.e., for $a_{D}=a_{A}=1$ ):

$$
k_{e p}=\frac{a_{D}^{d}\left(\mathrm{p}_{H} / \mathrm{p}\right)^{h}}{a_{A}^{a}\left(\mathrm{p}_{b} / \mathrm{p}\right)^{b}}=\frac{p_{H}^{h}}{p_{B}^{b}} \times p^{b-h}
$$

where $a_{i}$ is the activity of component $i$, and $p$ is normal pressure. 
Hence, it followed from Equations (3) and (4):

$$
h \lg p_{H}=\frac{\Delta_{r} G_{T}^{\theta}}{2.303 R T}+b \lg p_{B}+(\mathrm{b}-\mathrm{h}) \lg p
$$

where $k_{e p}$ was the thermodynamic equilibrium constant of the reaction at any temperature; $p_{i}$ was the equilibrium partial pressure of gaseous component $i$; $R$ was the universal gas constant; and $T$ was the reaction temperature in Kelvin.

The species that existed in Mn-S-O systems were $\mathrm{O}_{2}, \mathrm{SO}_{2}, \mathrm{Mn}, \mathrm{MnO}, \mathrm{MnO}_{2}, \mathrm{Mn}_{2} \mathrm{O}_{3}, \mathrm{Mn}_{3} \mathrm{O}_{4}$, $\mathrm{MnS}, \mathrm{MnS}_{2}$ and $\mathrm{MnSO}_{4}$. The thermodynamic properties of these species were gathered in Table 1.

Table 1. Thermodynamic properties of species in the Mn-S-O system.

\begin{tabular}{|c|c|c|c|c|c|c|c|c|}
\hline \multirow{2}{*}{ Number } & \multirow{2}{*}{ Compounds } & \multirow{2}{*}{$\begin{array}{c}\text { Temperature } \\
\text { Range (K) }\end{array}$} & \multirow{2}{*}{$\begin{array}{c}\Delta H_{298.15}^{\theta} \\
\left.\mathbf{( J \cdot} \cdot \mathbf{~ m o l}^{-1}\right)\end{array}$} & \multirow{2}{*}{$\begin{array}{c}\Delta_{r} H_{298.15}^{\theta} \\
\left(\mathbf{k J} \cdot \mathbf{~ m o l}^{-1}\right)\end{array}$} & \multicolumn{4}{|c|}{$c_{p}(T)=a+b T+c T^{2}+d T^{-2}$} \\
\hline & & & & & $a$ & $b$ & $c$ & $d$ \\
\hline 1 & $\mathrm{O}_{2}(g)$ & $298.15-1000.00$ & 0 & 205.03 & 26.92 & $1.69 \times 10^{-2}$ & $-6.76 \times 10^{-6}$ & $2.29 \times 10^{5}$ \\
\hline 2 & $\mathrm{SO}_{2}(g)$ & $298.15-1700.00$ & $-296,842.00$ & 248.10 & 53.02 & $4.34 \times 10^{-5}$ & $-24,439.25$ & $2.28 \times 10^{6}$ \\
\hline 3 & $\operatorname{Mn}(s)$ & $298.15-980.00$ & 0 & 32.01 & 23.85 & $1.41 \times 10^{-2}$ & & $-1.57 \times 10^{5}$ \\
\hline 4 & $\mathrm{MnO}(s)$ & $298.15-2115.15$ & $-384,928.00$ & 59.83 & 46.48 & $8.11 \times 10^{-3}$ & & $-3.68 \times 10^{5}$ \\
\hline 5 & $\mathrm{MnO}_{2}(s)$ & $298.15-523.00$ & $-520,071.20$ & 53.13 & 69.45 & $1.02 \times 10^{-2}$ & & $-1.62 \times 10^{6}$ \\
\hline 6 & $\mathrm{Mn}_{2} \mathrm{O}_{3}(s)$ & $298.15-1350.00$ & $-956,880.80$ & 110.45 & 103.47 & $3.50 \times 10^{-2}$ & & $-1.35 \times 10^{6}$ \\
\hline 7 & $\mathrm{Mn}_{3} \mathrm{O}_{4}(s)$ & $298.15-1445.00$ & $-1,386,577.60$ & 153.97 & 144.93 & $4.52 \times 10^{-2}$ & & $-9.20 \times 10^{5}$ \\
\hline 8 & $\operatorname{MnS}(s)$ & $298.15-1803.00$ & $-213,384.00$ & 80.33 & 47.69 & $7.53 \times 10^{-3}$ & & - \\
\hline 9 & $\mathrm{MnS}_{2}(s)$ & $298.15-700.00$ & $-223,844.00$ & 99.91 & 69.70 & $1.97 \times 10^{-2}$ & & $-4.35 \times 10^{5}$ \\
\hline 10 & $\mathrm{MnSO}_{4}(s)$ & 298.15-973.00 & $-1,065,246.40$ & 112.13 & 122.42 & $3.73 \times 10^{-2}$ & & $-2.94 \times 10^{6}$ \\
\hline
\end{tabular}

The equilibrium reaction and its enthalpy, entropy at the temperature of $298.15 \mathrm{~K}$, and the Gibbs free energy were listed in Table 2. Additionally, Equation (3) could be used to calculate the equilibrium constant $\left(k_{e p}\right)$.

Table 2. The enthalpy, entropy and Gibbs free energy of the equilibrium reaction.

\begin{tabular}{|c|c|c|c|c|}
\hline Number & Equilibrium Reaction & $\begin{array}{c}\Delta_{r} H_{298.15}^{\theta} \\
\left(\mathbf{k J} \cdot \mathbf{m o l}^{-1}\right)\end{array}$ & $\begin{array}{c}\Delta_{r} S_{298.15}^{\theta} \\
\left.\mathbf{( J \cdot} \cdot \mathbf{m o l}^{-1} \cdot \mathbf{K}^{-1}\right)\end{array}$ & $\begin{array}{c}\Delta_{r} G_{\mathbf{T}}^{\theta} \\
\left.\mathbf{( J \cdot} \cdot \mathbf{m o l}^{-1}\right)\end{array}$ \\
\hline 1 & $\mathrm{MnO}_{2}(s)+\mathrm{SO}_{2}(g)=\mathrm{MnSO}_{4}(s)$ & -248.33 & -189.10 & $-249,514.77+185.47 T-0.058 T \times \ln T-0.013 T^{2}$ \\
\hline 2 & $\mathrm{MnS}(s)+2 \mathrm{O}_{2}(g)=\mathrm{MnSO}_{4}(s)$ & -851.86 & -278.27 & $-858,263.65+237.58 T+20.87 T \times \ln T-0.002 T^{2}$ \\
\hline 3 & $\mathrm{MnS}(s)+\mathrm{O}_{2}(g)=\mathrm{Mn}(s)+\mathrm{SO}_{2}(g)$ & -83.45 & -5.25 & $-83,230.03-11.33 T+2.25 \mathrm{~T} \times \ln T-0.005 T^{2}$ \\
\hline 4 & $2 \mathrm{MnS}(s)+3 \mathrm{O}_{2}(g)=2 \mathrm{MnO}(s)+2 \mathrm{SO}_{2}(g)$ & -936.77 & -159.91 & $-945,800.8-0.05 T+22.84 T \times \ln T-0.025 T^{2}$ \\
\hline 5 & $2 \mathrm{Mn}(s)+\mathrm{O}_{2}(g)=2 \mathrm{MnS}(s)$ & -769.85 & -149.39 & $-776,608.38+22.26 T+18.34 T \times \ln T-0.014 T^{2}$ \\
\hline 6 & $6 \mathrm{MnO}(s)+\mathrm{O}_{2}(g)=2 \mathrm{Mn}_{3} \mathrm{O}_{4}(s)$ & -463.58 & -256.08 & $-457,727.62+366.54 T-15.93 T \times \ln T+0.012 T^{2}$ \\
\hline 7 & $4 \mathrm{Mn}_{3} \mathrm{O}_{4}(s)+\mathrm{O}_{2}(g)=6 \mathrm{Mn}_{2} \mathrm{O}_{3}(s)$ & -194.97 & -158.17 & $-198,662.44+65.10 T+14.16 T \times \ln T-0.006 T^{2}$ \\
\hline 8 & $2 \mathrm{Mn}_{2} \mathrm{O}_{3}(s)+\mathrm{O}_{2}(g)=4 \mathrm{MnO}_{2}(s)$ & -166.52 & -213.40 & $-181,663.38-87.79 T+43.95 T \times \ln T-0.023 T^{2}$ \\
\hline 9 & $2 \mathrm{MnO}(s)+2 \mathrm{SO}_{2}(g)+\mathrm{O}_{2}(g)=2 \mathrm{MnSO}_{4}(s)$ & -766.95 & -596.63 & $-770,722.50+476.26 T+18.90 T \times \ln T+0.021 T^{2}$ \\
\hline 10 & $2 \mathrm{Mn}_{2} \mathrm{O}_{3}(s)+4 \mathrm{SO}_{2}(g)+\mathrm{O}_{2}(g)=4 \mathrm{MnSO}_{4}(s)$ & -1159.85 & -969.82 & $-1,159,856.00+686.34 T+43.72 T \times \ln T+0.031 T^{2}$ \\
\hline 11 & $\mathrm{Mn}_{3} \mathrm{O}_{4}(s)+3 \mathrm{SO}_{2}(g)+\mathrm{O}_{2}(g)=3 \mathrm{MnSO}_{4}(s)$ & -918.63 & -466.91 & $-928,352.18+531.05 T+36.33 T \times \ln T+0.025 T^{2}$ \\
\hline 12 & $\mathrm{MnS}_{2}(s)+\mathrm{O}_{2}(g)=\mathrm{MnS}(s)+\mathrm{SO}_{2}(g)$ & -286.38 & 23.48 & $-288,889.96-55.22 T+4.09 T \times \ln T-0.014 T^{2}$ \\
\hline 13 & $\mathrm{MnS}_{2}(s)+3 \mathrm{O}_{2}(g)=\mathrm{MnSO}_{4}(s)+\mathrm{SO}_{2}(g)$ & -1138.24 & -354.79 & $-1,147,151.62+182.63 T+24.97 T \times \ln T-0.016 T^{2}$ \\
\hline 14 & $3 \mathrm{MnS}(s)+5 \mathrm{O}_{2}(g)=\mathrm{Mn}_{3} \mathrm{O}_{4}(s)+3 \mathrm{SO}_{2}(g)$ & -1636.95 & -367.91 & $-1,647,542.81+182.52 T+26.3 T \times \ln T-0.031 T^{2}$ \\
\hline
\end{tabular}

\section{Results and Discussion}

\subsection{Predominance area of $\mathrm{Mn}-\mathrm{S}-\mathrm{O}$}

The compounds involved in this diagram were stable within a predominance region, bordered by lines that represent the coexistence with other phases. The slope of each curve was determined by the stoichiometric coefficients of the corresponding reaction. Figure 1 indicated that manganese sulfate was the major chemical substance occurring during flue gas desulfurization by $\mathrm{MnO}_{2}$ or other manganese oxides. It also illustrated that $\mathrm{MnO}_{2}$, the main component of pyrolusite, can remove sulfur oxides to the level of government regulations, and the emission limit of sulfur oxides for the current sintering process is $600 \mathrm{mg} / \mathrm{m}^{3}$ in China. 


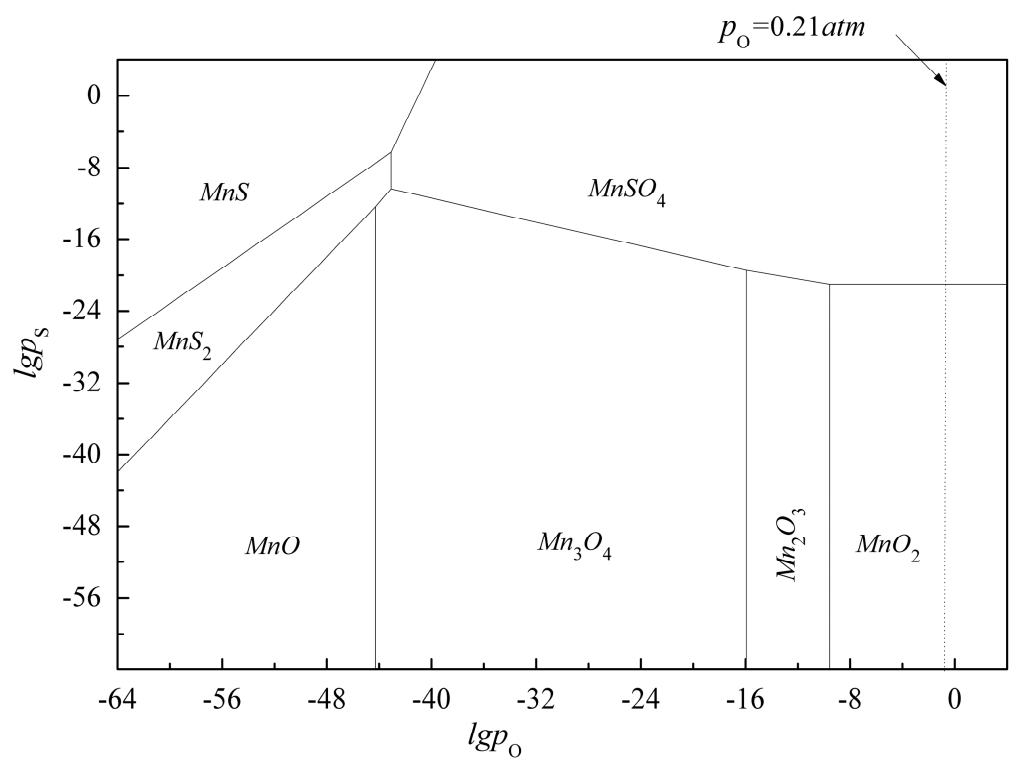

Figure 1. Predominance area of Mn-S-O system at $420 \mathrm{~K}$.

The extent of desulfurization achieved depended on the temperature and the gas composition. To obtain the desired and high value by-product, the conditions of desulfurization must be carefully controlled. The off-gas flows of the sinter machine were volatile, approximately reaching a value range of 500,000 to $2,000,000 \mathrm{Nm}^{3} / \mathrm{h}$ (NTP) [11], with a $\mathrm{SO}_{2}$ concentration from $0.05 \%$ to $0.23 \%$. According to Number 1 in Table 2, as the $\mathrm{SO}_{2}$ partial pressure decreases along with the vertical downward dotted line, the value $0.21 \mathrm{~atm}$ represents the $\mathrm{O}_{2}$ partial pressure in the atmospheric pressure, and the balance moved forward and arrived at the equilibrium boundary of $\mathrm{MnO}_{2} / \mathrm{MnSO}_{4}$, to approach an equilibrium value $\left(10^{-21}\right)$, which is shown in Figure 1 . In addition, the low valence manganese oxides achieve equilibrium with $\mathrm{MnSO}_{4}$ more easily. This implies that $\mathrm{MnSO}_{4}$ is the stable form of manganese for the manganese-containing flue gas desulfurization.

There are four stable oxides of manganese: $\mathrm{MnO}, \mathrm{Mn}_{3} \mathrm{O}_{4}, \mathrm{Mn}_{2} \mathrm{O}_{3}$ and $\mathrm{MnO}_{2}$. The reactions with $\mathrm{SO}_{2}$, such as NO. 1, NO. 9, NO. 10 and NO. 11 in Table 2, however, were very exothermic and the Gibbs free energy was negative. From Figure 1, it also can be found that they are appropriate for desulfurization.

\subsection{The Influence of Temperature on Dry Desulfurization}

The goal of flue gas desulfurization was to restore $\mathrm{SO}_{2}$ by $\mathrm{MnO}_{2}$ forming a solid end-product. Hence, the process was reduction of manganese oxide to manganese sulfite using sintering flue gas. The depth of desulfurization achieved depended on the temperature and gas composition. Importantly, the involved reaction of the Mn-S-O systems containing manganese oxides was exothermic. Therefore, temperatures must be carefully chosen to keep the reactivity and physical durability of the manganese ores. High temperatures may cause surface packing, leading pyrolusite reactivity to reduce greatly through the substantial loss of porosity $[20,21]$. Relatively low temperatures may result in a low reaction velocity and mass transfer rate. The effect of temperature was displayed by the predominance area diagram of the Mn-S-O systems at 350 K, 400 K, $500 \mathrm{~K}$ and $600 \mathrm{~K}$, as shown in Figure 2.

It was seen from Figure 2, as the temperature was increased, that the slope of each boundary remains the same, but its position was moved toward the upper right-hand corner of the diagram, further limiting the region of stability of the manganese sulfate. Additionally, as the temperature decreased, fewer residuals of $\mathrm{SO}_{2}$ are found in the clean gas. An appropriate temperature can ensure the efficiency of the reaction, thus eliminating the diffusion control caused by blocking the product surface. However, the operating temperature was determined by the macroscopic properties of the 
minerals and desulfurization process. It also can be found that desulfurization at $600 \mathrm{~K}$ was more efficient than at $350 \mathrm{~K}$. More importantly, the fuel gas of the sintering process discharge temperatures was about $120^{\circ} \mathrm{C}$ to $180{ }^{\circ} \mathrm{C}[11,12]$. We concluded that the discharge temperatures were the ideal reaction temperature range and the flue gas could be desulfurized directly without further cooling or heating means.
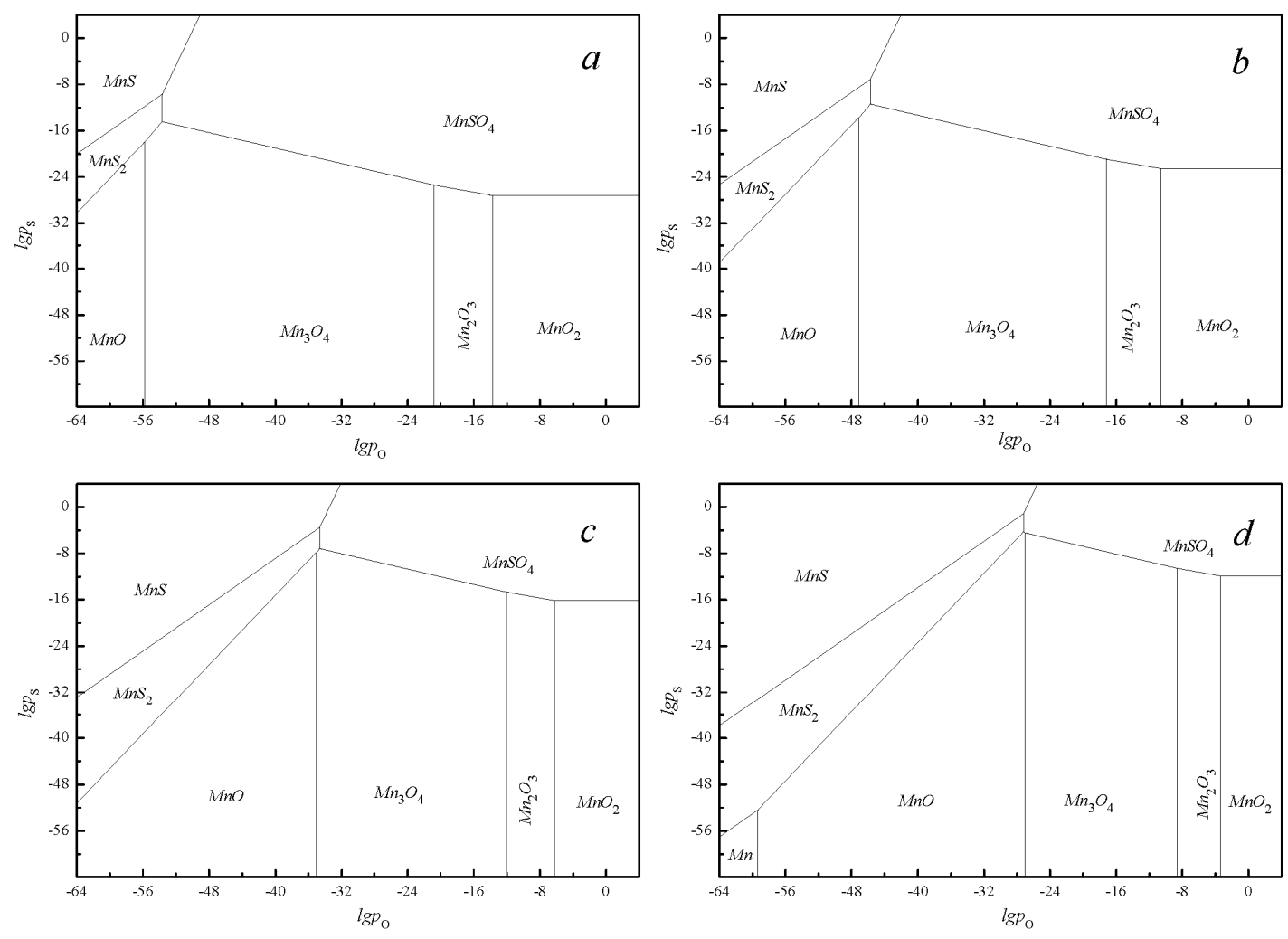

Figure 2. Predominance area diagram of Mn-S-O system: (a) 350 K; (b) $400 \mathrm{~K}$; (c) 500 K; (d) $600 \mathrm{~K}$.

This type of above presentation does not show the effect of temperatures, however. This could be directly achieved by plotting $\lg p_{\mathrm{S}}$ versus temperature, or better yet against reciprocal temperature, for a constant $\mathrm{O}_{2}$ pressure, as shown in Figure 3.

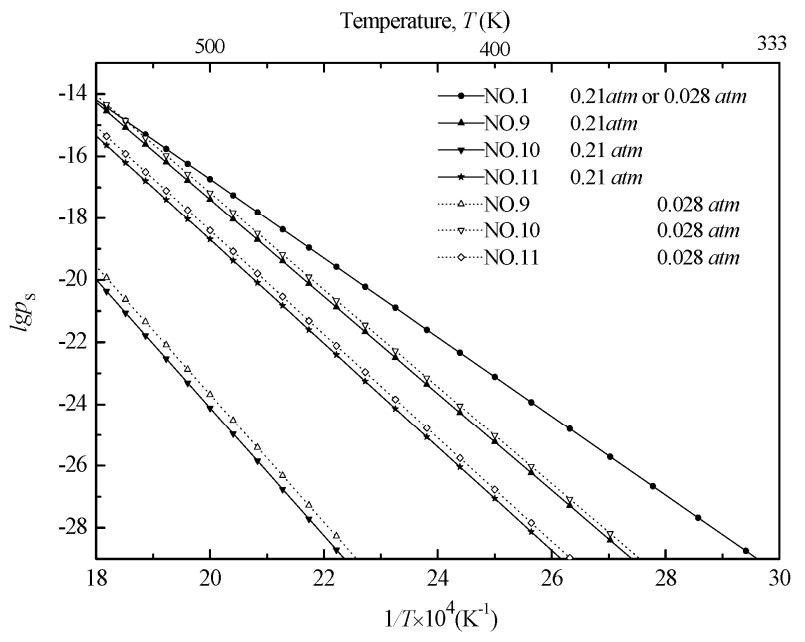

Figure 3. Effect of temperature on phase equilibrium in the Mn-S-O system at constant $\mathrm{O}_{2}$ partial pressure, $p_{\text {total }}=1 \mathrm{~atm}$. 
According to Figure 3, the former value was selected because it represents the $\mathrm{O}_{2}$ partial pressure in atmospheric pressure, and the latter value was selected according to Ref. [22]. As the $\mathrm{O}_{2}$ partial pressure decreases, the regions of sulfur dioxide stability expand while those of the sulfide and sulfate diminish. The effect of temperatures during desulfurization was consistent with the above discussion. Additionally, the low valence manganese oxides can readily oxidize sulfur dioxide to manganese sulfate even in low $\mathrm{O}_{2}$ partial pressure. It was also clear that the equilibriums of $\mathrm{MnO} / \mathrm{Mn}_{3} \mathrm{O}_{4}$ and $\mathrm{Mn}_{3} \mathrm{O}_{4} / \mathrm{Mn}_{2} \mathrm{O}_{3}$ are independent of the $\mathrm{SO}_{2}$ partial pressure.

\subsection{The Overlap Area of Mn-S-O and Fe-S-O Systems}

Pyrolusite, the main component of manganese oxide, was a mixtures of many substances, including silica, iron, aluminum, calcium, and other materials [23]. Iron oxide was considered to be a very promising and attractive sorbet for high-temperature desulfurization $[5,22,24]$ because of its favorable sulfation thermodynamics.

The thermodynamic condition can be obtained from the overlap diagram of the Mn-S-O and Fe-S-O systems, as shown in Figure 4.

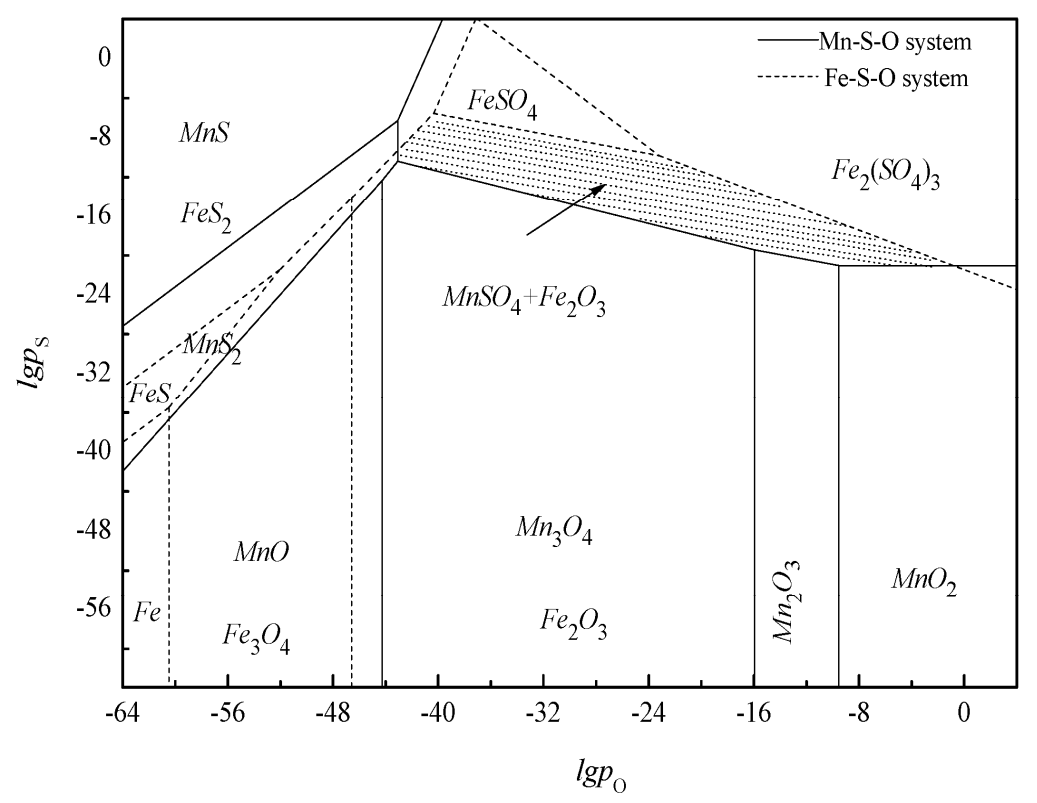

Figure 4. The overlap area of Mn-S-O system and Fe-S-O system at $420 \mathrm{~K}$.

As indicated in the figure, ferric oxide in pyrolusite may be transformed to ferric sulfate or ferrous sulfate by $\mathrm{SO}_{2}$, which is soluble in the water solution, thus making co-precipitates and bringing some trouble to the subsequent processing. Theoretical guidelines may be deduced from Figure 4 to avoid the possibility of formation of sulfate ferric during desulfurization. The location of the shaded region on the diagram is the coexistent stability region of $\mathrm{MnSO}_{4}$ and $\mathrm{Fe}_{2} \mathrm{O}_{3}$. By using an appropriate thermodynamic condition, $\mathrm{MnO}_{2}$ can be sulfated without sulfide and sulfate of iron. Besides, the manganese oxides exhibit great chemical activity and more complex mineralogical composition than ferric oxide at high temperatures [24,25], which are available to partition manganese and ferric oxides into different mineral phases and chemical forms by selective sulfation.

The sintering fuel gas includes a significant amount of $\mathrm{SO}_{2}$ and $\mathrm{NO}_{x}$, together with a small amount of entrained solid particles such as fly ash and other heavy metals. Manganese minerals can remove the above-mentioned waste at the same time to meet the stringent government regulations, achieving the goal of recovery of a high value manganese-containing end-product economically. In addition, the amount of entrained solid particles is more or less than manganese oxides, thus leading a slight influence to the efficiency of desulfurization. 
Manganese minerals are of potential commercial interest because in addition to Mn they also contain significant amounts (several tenths to more than one weight percent) of $\mathrm{Fe}, \mathrm{Ca}, \mathrm{Ni}, \mathrm{Co}$, and other strategic metals [26-28]. The thermodynamic analysis only shows the feasibility of dry desulfurization by manganese oxides. The actual process of desulfurization was a solid-gas reaction; the efficiency of desulfurization may be controlled by gas film diffusion, product layer diffusion, and surface reaction. How to increase the efficiency of flue gas desulfurization requires a deep insight into the thorough and detailed understanding of the atomic structures and crystal chemistries of manganese oxide minerals and the reaction mechanism of the solid-gas phase. Some kinetic studies of sulfur dioxide absorption by manganese should be further discussed.

\section{Conclusions}

As presented by the predominance area diagram of the Mn-S-O system, the removal of sulfur dioxide by using manganese oxides from sintering flue gas at discharge temperatures was able to meet the government regulations.

According to the predominance area diagram presented above at different temperatures, the flue gas could be desulfurized directly without further cooling or heating means which potentially offers significant thermal efficiency benefits.

The overlap of the predominance areas of the Mn-S-O and Fe-S-O systems indicated that both manganese and iron have the ability to desulfurize. By using an appropriate thermodynamic condition, a method of selective sulfation can lead manganese and ferric oxides into different mineral phases and chemical forms. The natural manganese resources, including manganese noudles and pyrolusite, provide a practical and extremely effective way for flue gas desulfurization, due to their large surface area and high chemical activity.

The predominance areas of $\mathrm{Mn} / \mathrm{Fe}-\mathrm{S}-\mathrm{O}$ would offer an attractive way of determining optimum experimental conditions for dry desulfurization by low-grade manganese resources, detectibly yielding a high-value end-product.

Acknowledgments: The authors gratefully acknowledge the financial support of National Science Foundation of China (No. 51364005 \& 51574094), the Industrial Research Project of Guizhou Science \& Technology Department in 2013 (No. 3009), and the Laboratory Projects numbered 4002 and 222 in 2014 of Guizhou Science \& Technology Department and Guizhou Education Department, respectively. The authors wish to express their very sincerely thanks to the reviewers for the valuable comments and suggestions.

Author Contributions: During the research of this project, Wenhao Wang and Keke Wang benefitted from suggestions and critical insights provided by Fuzhong Wu and Huixin Jin. Wenhao Wang searched out all the date used in this paper and wrote the bulk of the description, and calculation was partly finished by Keke Wang. All four were involved in organizing and refining the paper.

Conflicts of Interest: The authors declare no conflict of interest.

\section{Abbreviations}

The following abbreviations are used in this manuscript:

$a$

$a_{i}$

A

$b$

B

$c_{p}$

$d$

$D$

$\Delta G$

$\Delta H$ stoichiometric coefficients of component $A$

activity of component $i$

component $A$

stoichiometric coefficients of component $B$

component $B$

specific heat capacity, $\mathrm{kJ} \cdot \mathrm{mol}^{-1} \cdot \mathrm{K}^{-1}$

stoichiometric coefficients of component $D$

component $D$

Gibbs free energy change, $\mathrm{kJ} \cdot \mathrm{mol}^{-1}$

enthalpy change, $\mathrm{kJ} \cdot \mathrm{mol}^{-1}$ 
$h$

$H$

$k_{e p}$

$p_{i}$

$p_{S}$

$p_{O}$

$p$

$R$

$\Delta S$

$T$ stoichiometric coefficients of component $H$

component $H$

thermodynamic equilibrium constant of reaction

equilibrium partial pressure of gaseous component $i, \mathrm{~Pa}$

equilibrium partial pressure of $\mathrm{SO}_{2}$ gas, $\mathrm{Pa}$

equilibrium partial pressure of $\mathrm{O}_{2}$ gas, $\mathrm{Pa}$

normal pressure, $101325 \mathrm{~Pa}$

universal gas constant

entropy change, $\mathrm{J} \cdot \mathrm{mol}^{-1} \cdot \mathrm{K}^{-1}$

temperature, $\mathrm{K}$

\section{References}

1. Nelson, H.W.; Lyons, C.J. Sources and control of sulfur-bearing pollutants. J. Air Pollut. Control Assoc. 1957, 7, 187-193. [CrossRef]

2. Yan, Z.; Liu, L.; Zhang, Y.; Liang, J.; Wang, J.; Zhang, Z.; Wang, X. Activated semi-coke in $\mathrm{SO}_{2}$ removal from flue gas: Selection of activation methodology and desulfurization mechanism study. Energy Fuels 2013, 27, 3080-3089. [CrossRef]

3. Liu, Y.; Bisson, T.M.; Yang, H.; Xu, Z. Recent developments in novel sorbents for flue gas clean up. Fuel Process. Technol. 2010, 91, 1175-1197. [CrossRef]

4. Slack, A. Removing sulfur dioxide from stack gases. Environ. Sci. Technol. 1973, 7, 110-119. [CrossRef]

5. Gavaskar, V.S.; Abbasian, J. Dry regenerable metal oxide sorbents for $\mathrm{SO}_{2}$ removal from flue gases. Development and evaluation of copper oxide sorbents. Ind. Eng. Chem. Res. 2006, 45, 5859-5869.

6. Srivastava, R.K.; Jozewicz, W. Flue gas desulfurization: The state of the art. J. Air Waste Manag. Assoc. 2001, 51, 1676-1688. [CrossRef] [PubMed]

7. Taylor, M.R.; Rubin, E.S.; Hounshell, D.A. Effect of government actions on technological innovation for $\mathrm{SO}_{2}$ control. Environ. Sci. Technol. 2003, 37, 4527-4534. [CrossRef] [PubMed]

8. Raisoni, P.R.; Dixit, S.G. Leaching of manganese ore with aqueous sulphur dioxide solutions. Bull. Mater. Sci. 1988, 10, 479-483. [CrossRef]

9. Kanungo, S.; Das, R. Extraction of metals from manganese nodules of the indian ocean by leaching in aqueous solution of sulphur dioxide. Hydrometallurgy 1988, 20, 135-146. [CrossRef]

10. Sun, W.-Y.; Ding, S.-L.; Zeng, S.-S.; Su, S.-J.; Jiang, W.-J. Simultaneous absorption of $\mathrm{NO}_{x}$ and $\mathrm{SO}_{2}$ from flue gas with pyrolusite slurry combined with gas-phase oxidation of no using ozone. J. Hazard. Mater. 2011, 192, 124-130. [CrossRef] [PubMed]

11. Fleischanderl, A.; Plattner, T.; Lanzerstorfer, C. Efficient reduction of PM 10/2.5 emissions at iron ore sinter plants. Proc. Dust Conf. 2007, 2007, 23-24.

12. Liu, Z.; Zhang, J.; Yang, T. Research and development of sintering flue gas desulphurization technology. China Metal. 2009, 19, 1-5.

13. Liu, Y.; Sun, J.; Hu, X.-X.; Shu, S.-J.; Ding, S.-L.; Yu, Z.-L. Study on flue gas desulfurization with rhodochrosite and pyrolusite pulp. China's Manganese Ind. 2008, 26, 19-23.

14. Van Hecke, M.; Bartlett, R. Kinetics of sulfation of atlantic ocean manganese nodules. Metall. Trans. 1973, 4, 941-947. [CrossRef]

15. Kiang, K.D.; Li, K.; Rothfus, R.R. Kinetic studies of sulfur dioxide absorption by manganese dioxide. Environ. Sci. Technol. 1976, 10, 886-893. [CrossRef]

16. Lacey, D.; Bowen, J.; Basden, K. Theory of noncatalytic gas-solid reactions. Ind. Eng. Chem. Fundam. 1965, 4, 275-281. [CrossRef]

17. Ingraham, T.; Marier, P. Kinetics of the formation of $\mathrm{MnSO}_{4}$ from $\mathrm{MnO}_{2}, \mathrm{Mn}_{2} \mathrm{O}_{3}$, and $\mathrm{Mn}_{3} \mathrm{O}_{4}$ and its decomposition to $\mathrm{Mn}_{2} \mathrm{O}_{3}$ or $\mathrm{Mn}_{3} \mathrm{O}_{4}$. Trans. Metall. Soc. AIME 1968, 242, $2039-2043$.

18. Li, K.; Rothfus, R.; Adey, A. Effect of macroscopic properties of manganese oxides on absorption of sulfur dioxide. Environ. Sci. Technol. 1968, 2, 619-621. [CrossRef]

19. Uno, T.; Fukui, S.; Atsukawa, M.; Higashi, M.; Yamada, H.; Kamei, $\mathrm{K} . ~^{\mathrm{SO}_{2}}$ conversion-6. Scale-up of a $\mathrm{SO}_{2}$ control process: Up to $90 \%$ S dioxide removal effected by use of Mn oxide. Chem. Eng. Prog. 1970, 66, 61-65. 
20. Slimane, R.B.; Abbasian, J. Copper-based sorbents for coal gas desulfurization at moderate temperatures. Ind. Eng. Chem. Res. 2000, 39, 1338-1344. [CrossRef]

21. Bienstock, D.; Field, F. Bench-scale investigation on removing sulfur dioxide from flue gases. J. Air Pollut. Control Assoc. 1960, 10, 121-125. [CrossRef] [PubMed]

22. Lowell, P.S.; Schwitzgebel, K.; Parsons, T.B.; Sladek, K.J. Selection of metal oxides for removing $\mathrm{SO}_{2}$ from flue gas. Ind. Eng. Chem. Process Design Dev. 1971, 10, 384-390. [CrossRef]

23. Zhang, W.; Cheng, C.Y. Manganese metallurgy review. Part I: Leaching of ores/secondary materials and recovery of electrolytic/chemical manganese dioxide. Hydrometallurgy 2007, 89, 137-159.

24. Uysal, B.Z.; Aksahin, I.; Yucel, H. Sorption of sulfur dioxide on metal oxides in a fluidized bed. Ind. Eng. Chem. Res. 1988, 27, 434-439. [CrossRef]

25. Chao, T.; Theobald, P. The significance of secondary iron and manganese oxides in geochemical exploration. Econ. Geol. 1976, 71, 1560-1569. [CrossRef]

26. Post, J.E. Manganese oxide minerals: Crystal structures and economic and environmental significance. Proc. Natl. Acad. Sci. USA 1999, 96, 3447-3454. [CrossRef] [PubMed]

27. Jenne, E.A. Controls on $\mathrm{Mn}, \mathrm{Fe}, \mathrm{Co}, \mathrm{Ni}, \mathrm{Cu}$, and $\mathrm{Zn}$ concentrations in soils and water: The significant role of hydrous mn and fe oxides. Adv. Chem. Ser. 1968, 1968, 337-387.

28. Young, L.B.; Harvey, H.H. The relative importance of manganese and iron oxides and organic matter in the sorption of trace metals by surficial lake sediments. Geochim. Cosmochim. Acta 1992, 56, 1175-1186. [CrossRef]

(C) 2016 by the authors; licensee MDPI, Basel, Switzerland. This article is an open access article distributed under the terms and conditions of the Creative Commons by Attribution (CC-BY) license (http://creativecommons.org/licenses/by/4.0/). 